ISSN 1112-9867

\title{
ACHIEVEMENT OF COURSE OUTCOME IN VECTOR CALCULUS PRE-TEST QUESTIONS
}

\author{
N. Lohgheswary ${ }^{1, *}$, Z. M. Nopiah ${ }^{2}$, A. A. Aziz ${ }^{3}$ and E. Zakaria ${ }^{4}$ \\ ${ }^{1}$ Faculty of Engineering and Built Environment, SEGi University, Malaysia \\ ${ }^{2}$ Faculty of Engineering and Built Environment, Universiti Kebangsaan Malaysia, Malaysia \\ ${ }^{3}$ Faculty of Computing and IT, King Abdul Aziz University, Saudi Arabia \\ ${ }^{4}$ Faculty of Education, Universiti Kebangsaan Malaysia, Malaysia
}

Published online: 17 October 2017

\begin{abstract}
Vector Calculus is the basic engineering mathematics module for all other engineering modules.A good grasp of knowledge in Vector Calculus will ensure that students perform and understand other subsequent engineering modules. To achieve this objective, a pre-test on Vector Calculus was set up in semester 1 2015/2016. Pre-test questions were designed based on both the Course Outcome and Programme Outcome. In addition,the Bloom taxanomy level (knowledge to creation) was examined in all questions. The Rasch Measurement Model was used to analyze the result of the pre-test. Findings on summary statistics of items, summary statistics of person, fit statistics and item dimensionality give a detailed analysis on the pre-test. All the pre-test items / questions are acceptable and valid. The Vector Calculus pre-test questions achieved all the Course Outcome of the Vector Calculus syllabus.
\end{abstract}

Keywords: pre-test; course outcome; bloom taxanomy; Rasch measurement model; vector calculus.

Author Correspondence, e-mail: lohgheswarynagarethinam@gmail.com doi: http://dx.doi.org/10.4314/jfas.v9i5s.28 


\section{INTRODUCTION}

Mathematical knowledge is essential in all the engineering courses as the problem-solving abilities in mathematics will be applied directly to other engineering subjects. Thus, it is essential for engineering students to have a strong foundation in problem-solving skills in the freshman course to ensure that they do well in their subsequent years.

Amathematics'-pre-test was conducted to first year engineering students from UniversitiKebangsaan Malaysia (UKM) and this resulted in students having poor knowledge in certain Mathematics' topics [1]. Engineering students' performance and the factors influencing the performance in mathematics courses at the Faculty of Engineering and Built Environment were examined [2]. Findings show that the pre-test is a good indicator/predictor for students' performance.

Rasch Model is a suitable method to access students' ability. Rasch Model is used to validate the construct of measurement instruments [3]. The study concludes that the Rasch Model gives better in depth understanding about an attribute.

Rasch Measurement was further found useful to measure the achievement of course learning outcomes in information technology education [4]. Students are accurately classified by results according to their achievements by using Rasch Measurement. The study suggests that Rasch Measurement can be used to form valid measures on several dimensions of learning achievement. Students learning ability development can be tracked over their study period and teaching styles can be improved to facilitate latent development.

Dichotomous Rasch model 0 and 1 scoring of item was applied to analyse the reliability of the Linear Algebra questions [5]. The study recommends that the items are rephrased or replaced to reduce item gaps and exam questions should be arranged in order from the easiest to difficult, so that students have more time to answer the difficult questions.

Final exam questions for Differential Equation course were classified according to Bloom's cognitive level [6]. The analysis was complete using the Rasch Measurement Model. Although there is no misfit item yet, the final questions needed to be reviewed due to the large gap that exists in each level of Bloom's Taxanomy.

An entry test was conducted for the new engineering undergraduates to classify the students according to their ability in Mathematics [7]. The Rasch Measurement model is used to 
measure students' capability by considering the level of difficulty of all the items in the test. This study also reveals students' performance and it is able to group the students according to their performance.

Rasch Model was used to analyse 215 students' profiling and Linear Algebra results. Students' profile consists of gender, department, programme, pre-university qualifications and pre-university results [8]. These are the variables of the study. Students' final results are considered as another variable. The findings highlighted two variables, namely pre-universities qualification and sex. The study concludes that students with Malaysian Higher School Certificates (STPM) and male students perform well in engineering courses.

This paper focuses on the reliability of the pre-test Vector Calculus questions which were validated by the respective lecturers who are teaching that subject. The pre-test questions/items' reliability must maintain their relative difficulty on the same gap of the logit scale. The Rasch Measurement Model was used to identify the misfit questions/items.

\section{METHODOLOGY}

Five pre-test questions were designed for KKKQ 1124, Vector Calculus subject for the first year students from departments of Electrical, Electronic and System Engineering of Faculty of Engineering and Built Environment, UniversitiKebangsaan Malaysia. These pre-test questions were validated by two lecturers who teach the subject for this semester, that is semester 1 2015/2016.

The pre-test questions were designed as subjective questions and they included sub-questions which need to be solved within 2 hours and thisfurther contributes to a total of 40 marks. ProgrammeOutcome (PO) and Course Outcome (CO) are used as a basis to construct the pre-test questions/items.

The CO for the Vector Calculus subject is shown in Table 1 [9]. CO1 is not tested in this pre-test because the assessment method for $\mathrm{CO} 1$ is through e-learning. The PO is shown in Table 2. Only PO1 and PO2 and most of CO are examined for this study. 
Table 1. Course outcome for vector calculus subject

\section{CO Description}

1 Understand the basic of surfaces in space.

2 Able to apply the basic concepts of partial derivatives.

3 Understand and able to apply the concepts of vector function, vector field, scalar field, gradient, divergence and curl.

4 Able to apply the concepts of line integral, double integral and triple integral in solving engineering problems.

5 Able to apply Green's Theorem, Stokes' Theorem and Gauss' Theorem in solving engineering problems.

6 Understand basic concepts of differentiation and integration of complex functions.

Table 2.Programme outcome for vector calculus subject

\section{PO Description}

1 Engineering knowledge

2 Problem analysis

3 Design/development of solutions

4 Investigation

5 Modern tool usage

6 The engineer and society

7 Environment and sustainability

8 Ethics

9 Communication

10 Individual and team work

11 Life long learning

12 Project management and finance

The pre-test question numbers together with the CO, PO, Bloom Taxanomy and description are labeled in Table 3. 
Table 3.Entry number for each question

\begin{tabular}{lllll}
\hline QuestionCO & PO & $\begin{array}{c}\text { Bloom } \\
\text { Taxanomy }\end{array}$ \\
\hline 1 & 2 & 1 & 3 & Application \\
$2($ i) & 3 & 1 & 4 & Analysis \\
$2($ ii) & 3 & 1 & 3 & Application \\
3 & 4 & 1 & 5 & Evaluation \\
$4($ i) & 5 & 2 & 3 & Application \\
$4($ ii) & 5 & 2 & 5 & Evaluation \\
$4($ iii) & 5 & 2 & 2 & Comprehension \\
5 & 6 & 1 & 3 & Application \\
\hline
\end{tabular}

\section{RESULTS AND DISCUSSION}

The grades are compiled in the Excel *prn format. TheRasch analysis was performed using Bond and Box Steps which is customized as WINSTEPS to assess the student's achievement and the output was analysed [10]. Among the analyses that will be considered are Summary Statistics, Fit Statistics and Item Dimensionality Test.

\subsection{Summary Statistics}

The Summary statistics provides information on how well the questionnaire was constructed and how well the students attempted to answer the questions. Generally, the statistics summary provides ample information of the mean, standard deviation and maximum and minimum standard values for the individual (person) and items.

Fig. 1 shows the measurement of items/questions involved in this study. 'Item' represents the questions tested on the pre-test Vector Calculus subject. The item reliability is 0.93 which indicates good item difficulty spread. 


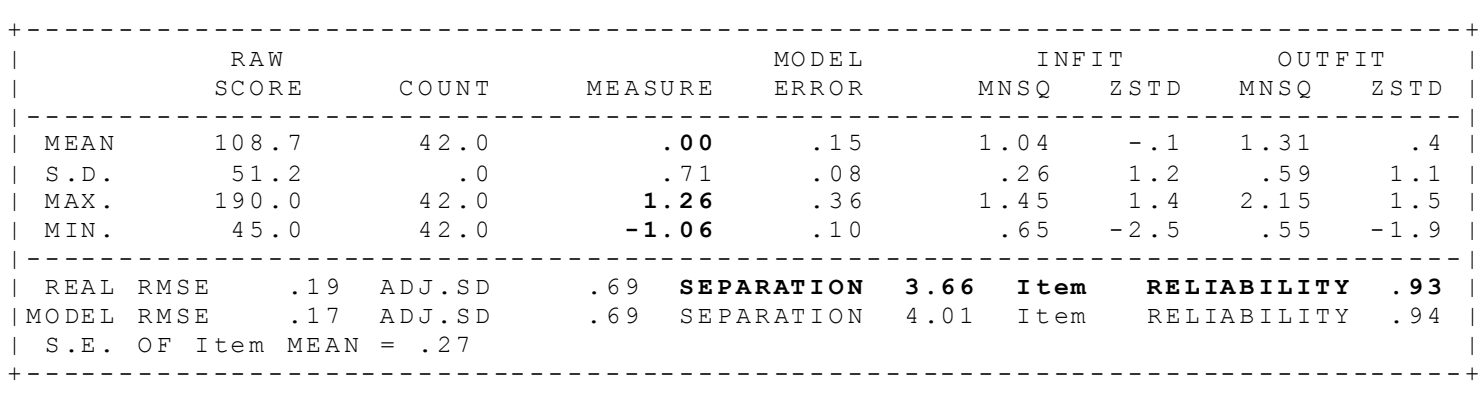

Fig.1. Summary ststistics for items

It can be noted that item mean is 0 . The item separation is 3.66 logit. This means the questions can be grouped roughly into four categories: very difficult, difficult, moderate and easy. The most difficult item on the logit ruler is +1.26 logit and the easiestitem on the ruler is located at -1.06 logit.

Fig. 2 shows a summary of the statistical results for the measurement of individual/person. Individuals represent the students who took Vector Calculus subject. The person reliability is 0.36. A reliability value below 0.7 indicates that the students provide irregular responses to the items. We assume they can answer the question, but in actual fact, they cannot. Some questions are less likely answerable, but they can also be answered successfully.

Separation is the index of spread of the person positions. The higher of separation values indicates the spread of items along the continuum [11]. If the separation value is lower, it means the lack of items in the study. The students cannot be divided into any group if the separation value is 1.0 logit or below. Logit forms equal the interval linear scale. This means that they have the same ability. Therefore, the rating scale applied will be revised for the study. From Fig. 2, the person separation is 0.74 logit. Therefore, the students cannot be divided into any group. Individual mean is -0.26 logit. The logit reflects that individual (student) performance is lower than the expected performance. The negative person mean indicates that the students failed to achieve the Blooms achievement in the COs. This "unachievement" explained by the fact that the mean is below 0.00 logit. This indicates that the students are less competent.

The highest item on the difficulty logit ruler is at +0.80 logit while the lowestitem is located at -1.08 logit. The difference between the maximum and minimum measures is moderate. This indicates that the measurement ruler of students' ability is similar or homogenous. They are of 
the same ability.

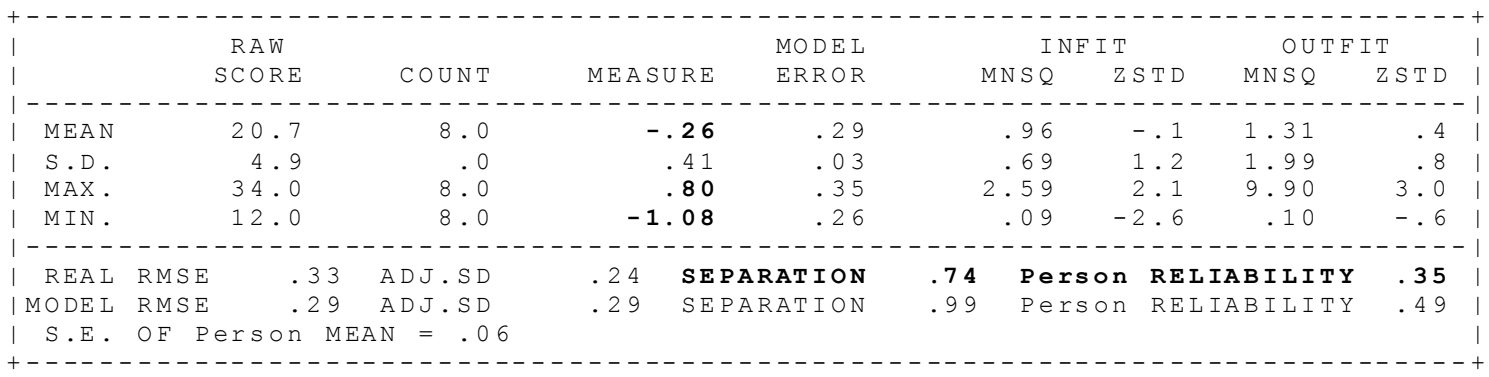

Fig.2. Summary ststistics for individual

\subsection{Fit Statistics}

Rasch examined the item fit by infit and outfit [12]. A Point-Measure Correlation (PMC) calculates the index of the item discrimination where the item with greater value might be too good compared to other items [9]. The acceptable region for the PMC is $0.4<x<0.8$. The Rasch analysis is able to identify inconsistency responses in an item, for instance students who are weaker at problem-solving are able to answer difficult items correctly using an outfit index.

Outfit Mean Square (MNSQ) is used to calculate the outfit index. The acceptable range for MNSQ is $0.5<M N S Q<1.5$. Consequently, its expected value is close to 1.0 . Values greater than 1.0 indicate other of variance in the data [10]. This degrades the measurement. Values less than 1.0 indicate that the model predicts the data too well.

Outfit z-standard too is used to calculate the outfit index. Outfit z-standard reports the statistical significance of the chi-square statistics occurring by chance when the data fit the Rasch model [10]. The acceptable region for z-standard is $-2<z<2$.

To determine a misfit item, a three-step comparison procedure is examined. Firstly, thePMC value is examined. Item 4(iii), item 4(ii) and item 5 are out of the range. Next, the MNSQ range is compared. Item 4(iii), item 4(ii) and 5 are out of range for MNSQ. Lastly, the z-standard is cross checked.All the items are within the z-standard range. A misfit item is identified if all three values are out of the acceptable region. Since item 4(ii), item 4 (iii) and item 5 are not out of range for all PMC, MNSQ and z-standard, those items are not misfit items. Therefore, no further action such as rephrasing or deleting the item is needed. 


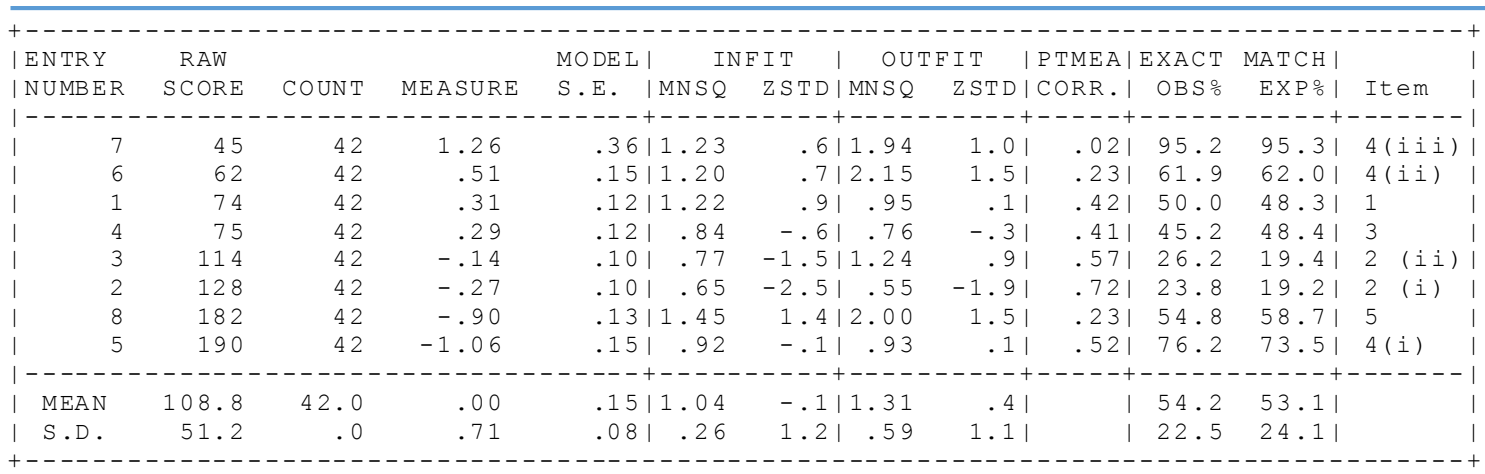

Fig.3.Meaure order

\subsection{Item Dimensionality Test}

The dimensionality of the instruments, the pretest is determined by the standard residual variance or the eigenvalues. Dimensionality means the 'direction' of the measurement. Table 4 shows that the result of item dimensionality is $41.1 \%$ where it is greater than $40 \%$ minimum mark. This can be obtained from raw unexplained variance (total). Therefore, the instrument is within acceptable dimensionality. There is also enough reliability in measuring the students' problem solving skills in Vector Calculus pre-test questions. The unexplained variance in the $1^{\text {st }}$ contrast explains $8 \%$ of the variance. This is within the range of 5\% to $15 \%$ [7]. Therefore, the test items are unidimensional.

Table 4.Item dimensionality

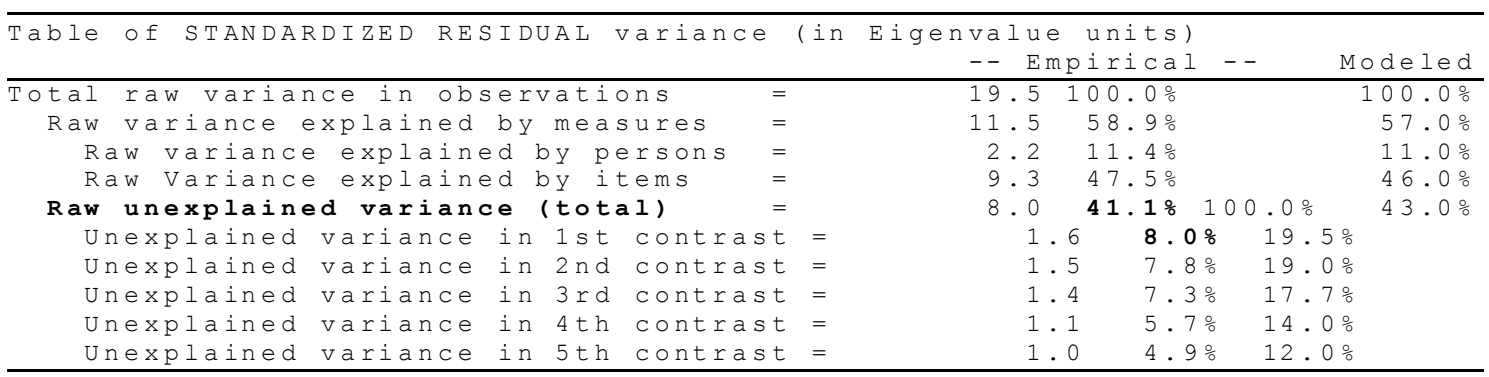

\section{CONCLUSION}

In this study, the pre-test questions/items for KKKQ1124 Vector Calculus subject were designed and constructed well and they were found to be very reliable as no questions/items were identified as misfit. Findings show that the persons and items involved in the study have good problem solving skills and different levels of difficulty spread, with an eigenvalue of the raw variable explained by the measure is more than $40 \%$. This indicates that the sample and 
the items are reliable in measuring the students' problem-solving skills.

The person reliability 0.35 shows that the items are insufficient. More items need to be added to test the students' ability. However, the performance of the fresh undergraduate students is lower than expected as their Mean Person is at -0.26 logit measures. This indicates that students could not answer all the questions within the $\mathrm{CO}$ and PO. This can be gathered from the high value of MNSQ and ZStd, indicating that the responses from the students are not predictable.

MNSQ greater than 1 indicates that students provide unpredictable responses. For example, a good student is assumed to be able to answer easy questions. Therefore, in other words, if more relevant items are provided in the test and with a variation of difficulties, possibly, the students might have a better chance to answer the questions.

All the CO and PO are tested well with the Bloom Taxanomy description in the pre-test questions. The Rasch Measurement Model enables each question (item) to be evaluated discretely and it is related to the Vector Calculus subject. The Rasch Measurement Modelable to identify the pre-test questions/items of difficulty for the students. In conclusion, the Rasch Measurement Model has been a very useful tool to verify the reliability of the pre-test questions for the Vector Calculus subject.

\section{ACKNOWLEDGEMENTS}

The authors wish to express their gratitude toSEGi University and UniversitiKebangsaan Malaysia for supporting the research.

\section{REFERENCES}

[1] Othman H, Ariff N A, Ismail N A, Asshaari N, Razali N A, Nopiah Z M. Engineering students' performance in mathematical courses: The case study of Faculty of Engineering and Built Environment, UniversitiKebangsaan Malaysia. In 1st Regional Conference on Applied and Engineering, 2010, pp. 512-516

[2]Ismail $\mathrm{N}$ A, Nopiah $\mathrm{Z}$ M, Asshaari I, Othman H, Tawil N M, Zaharim A. Mathematicalperformance on engineering studentsin UniversitiKebangsaan Malaysia.Procedia-Social and Behavioral Sciences, 2012, 60:206-211

[3] Azrilah A A, Azlinah M, Noor H A, Hamzah A G, Sohaimi Z, Saifudin M. Application of Raschmodel in validating the contruct measurement instrument. International Journal of 
Education and Information Technologies, 2008, 2(2):105-112

[4] Azlinah M, Azrilah A A, Sohaimi Z, Mohd S M. Appraisal of course learning outcomes using Rasch measurement: A case study in information technology education. In 7th WSEAS International Conference on Artificial Intelligence, Knowledge Engineering and Data Base, 2008, pp. 482-488

[5]Zulkifli M N, MohdH O, Noorhelyna R, Fadiah H M A, Izamarlina A. How good was the test set up? From Raschanalysis perspective. In Regional Conference on Engineering Education and Research in Higher Education, 2010, pp. 1-8

[6]Ashaari I, Othman H, Bahaludin H, Ismail N A, Nopiah Z M. Appraisal on Bloom's separation in final examination question on engineering mathematics cources using Rasch measurement model. Procedia-Social and Behavioral Sciences, 2012, 60:172-178

[7] Aziz A A, Zaharim A, Fuaad N F A, Nopiah Z M. Students' performance on engineering mathematics applyingRaschmeasurement model. In IEEE International Conference onInformation Technology Based Higher Education and Training, 2013, pp. 1-4

[8]Nopiah Z M, Ismail N A, Othman H, Asshaari I, Razali N, Osman M H, Jamaluddin M H. Identification of student achievement and academic profile in the linear algebra course: An analysis using the Rasch model. In 3rd International Congress on Engineering Education, 2011, pp. 197-202

[9]Othman H, Asshaari I, Bahaludin H, Nopiah Z M, Ismail N A. Application of Raschmeasurement model in reliability and quality evaluation of examination paper for engineering mathematics courses. Procedia-Social and Behavioral Sciences, 2012, 60:163-171

[10] Bond T G, Fox C M. Applying the Rasch model: Fundamental measurement in the human sciences.Abingdon-on-Thames: Routledge,2006

[11] Green K E. Survey development and validation with Rasch model. In International Conference on Questionnaire Development, Evaluation and Testing, 2002, pp. 1-42

[12]Draugalis J T, Jackson T R. Objective curricular evaluation: ApplyingRaschmodel to a cumulative examination. American Journal of PharmaceuticalEducation, 2004,68(2):1-12

\section{How to cite this article:}

Lohgheswary N, Nopiah Z M, Aziz A A and Zakaria E. Achievement of Course Outcome in Vector Calculus Pre-test Questions. J. Fundam. Appl. Sci., 2017, 9(5S), 394-403. 